\title{
Effectiveness and safety of ivabradine in the treatment of acute myocardial infarction: a systematic review and meta-analysis
}

\author{
Bo Wang ${ }^{1 \#}$, Xiaoxia Zhang ${ }^{2 \#}$, Jun Chen ${ }^{3}$, Shixiong Chen ${ }^{4}$, Qinghua Chen ${ }^{4}$, Senyan Yang ${ }^{5}$, Qiugui Wang ${ }^{2}$ \\ ${ }^{1}$ Department of Emergency, Hainan General Hospital (Hainan Affiliated Hospital of Hainan Medical University), Haikou, China; ${ }^{2}$ Department of \\ Internal Medicine, Danzhou People's Hospital, Danzhou, China; ${ }^{3}$ Department of Intensive Care Unit, Danzhou People's Hospital, Danzhou, China; \\ ${ }^{4}$ Department of Internal Medicine-Cardiovascular, Danzhou People's Hospital, Danzhou, China; ${ }^{5}$ Department of Cardiothoracic Oncology Surgery, \\ Danzhou People's Hospital, Danzhou, China \\ Contributions: (I) Conception and design: B Wang, X Zhang, Q Wang; (II) Administrative support: B Wang, Q Wang; (III) Provision of study \\ materials or patients: J Chen, S Chen, Q Chen, S Yang; (IV) Collection and assembly of data: All authors; (V) Data analysis and interpretation: B \\ Wang, X Zhang, S Yang; (VI) Manuscript writing: All authors; (VII) Final approval of manuscript: All authors. \\ "These authors contributed equally to this work. \\ Correspondence to: Qiugui Wang. Department of Internal Medicine, Danzhou People's Hospital, 21-1 Nada Town Datong Road, Danzhou 571700, \\ China. Email: wangqiugui8853@163.com.
}

Background Cardiovascular diseases have become a prominent threat to public health and quality of life. In recent years, some studies have reported that ivabradine can improve the cardiac function and prognosis of patients with acute myocardial infarction (AMI).

Methods: We searched China National Knowledge Infrastructure (CNKI), Wanfang database, Chinese Biomedical Literature (CBM), Chongqing Weipu Chinese Sci-tech Journal Database (VIP), PubMed, Cochrane Library, and EMBASE for randomized controlled trials (RCTs) of ivabradine in the treatment of AMI from January 1980 until December 2020. Each RCT was systematically reviewed.

Results: A total of 7 RCTs with 658 patients were included. Compared with the control group, the heart rate [mean deviation $(\mathrm{MD})=-9.20,95 \%$ confidence interval $(\mathrm{CI}):-13.03$ to $-5.38, \mathrm{P}<0.00001$ ] and brain natriuretic peptide (BNP) $(\mathrm{MD}=-112.73,95 \% \mathrm{CI}:-186.12$ to $-39.35, \mathrm{P}=0.003)$ of patients who received ivabradine combined with conventional standard treatment were significantly lower and left ventricular ejection fraction (LVEF) ( $\mathrm{MD}=3.17,95 \% \mathrm{CI}: 2.12$ to $4.23, \mathrm{P}<0.00001)$ was significantly better. The difference in adverse events was not statistically significant [odds ratio $(\mathrm{OR})=2.45,95 \%$ CI: 0.92 to 6.55 , $\mathrm{P}=0.07]$.

Discussion: Ivabradine combined with $\beta$-blockers can reduce the resting heart rate and improve heart function in patients with AMI while not increasing adverse events. However, due to limitations in the number and quality of studies included, our conclusions need to be further confirmed by analyzing more studies.

Keywords: Ivabradine; myocardial infarction; meta-analysis

Submitted Feb 05, 2021. Accepted for publication Apr 17, 2021.

doi: $10.21037 / \mathrm{apm}-21-563$

View this article at: http://dx.doi.org/10.21037/apm-21-563

\section{Introduction}

Cardiovascular diseases have become a prominent threat to public health and quality of life. As one of the most serious cardiovascular diseases, acute myocardial infarction (AMI) changes rapidly, comes with serious complications, and is characterized by high mortality (1). Therefore, controlling the heart rate has garnered increasing attention in the clinical treatment of AMI $(2,3)$. In standard treatment, $\beta$-blockers are the most widely used drugs to control heart rate, they can block the heart's beta receptors and lower 
the heart rate, thus improving the prognosis of patients with AMI $(4,5)$. Beside $\beta$-blockers, ivabradine can decrease the heart rate by prevention of upregulation of IF current, downregulating the sinoatrial node rhythm, and controlling the interval between the continuous cardiac action potential duration (6). In recent years, both local and international studies have reported that ivabradine can improve the cardiac function and prognosis of patients with AMI, however the research has been limited by small sample sizes of single-center studies, and inconsistent treatment courses, follow-up time, and results. Therefore, we aimed to evaluate the efficacy and safety of ivabradine in the treatment of AMI in this meta-analysis by systematically reviewing relevant local and international clinical studies of recent years, providing evidence for guiding the treatment of AMI. We present the following article in accordance with the PRISMA reporting checklist (available at http://dx.doi. org/10.21037/apm-21-563).

\section{Methods}

\section{Criteria for inclusion and exclusion}

\section{Study type}

We included randomized controlled trials (RCTs) published in China and internationally. Studies were restricted to those published in Chinese and English.

\section{Participants}

The diagnosis of AMI in all participants met the 2007 Chinese Medical Association Cardiovascular Branch (7) and the 2007 American Heart Association/American College of Cardiology (8) diagnostic criteria, regardless of age and gender.

\section{Intervention}

The experimental group was treated with ivabradine combined with the standard regime, and the control group was treated with the standard regime, with no restrictions on the dose and course of treatment.

\section{Outcome measures}

(I) Heart rate; (II) left ventricular ejection fraction (LVEF); (III) pro-brain natriuretic peptide (NT-proBNP); (IV) occurrence of adverse reactions.

\section{Exclusion criteria}

(I) Non-RCT studies; (II) studies published in neither
Chinese nor English languages; (III) duplicate studies, experience summaries, case reports, reviews, studies with incomplete information, animal experiments, meeting minutes; (IV) studies with fewer than 15 cases; (V) the loss rate of the subjects was $>20 \%$.

\section{Search strategy}

The databases searched included: (I) China National Knowledge Internet (CNKI); (II) Wanfang database; (III) Chinese Biomedical Database (CBM); (IV) Chongqing Weipu Chinese Sci-tech Journal Database (VIP); (V) PubMed; (VI) the Cochrane Library; (VII) Embase. Chinese search terms used were "acute myocardial infarction", "ivabradine", and so on. English search terms used were "acute myocardial infarction", "cardiovascular stroke", "heart attack", "myocardial infarct", and "ivabradine".

\section{Data extraction and quality assessment}

The Cochrane risk of bias assessment tool (9) was used to evaluate the quality of RCT. Items which we evaluated included: random allocation method, concealment of allocation, blinding method, integrity of resulting data, selective report research results, and other sources of bias.

\section{Data extraction}

General information (researchers, year of publication, countries, age of cases, sample size), intervention measures for experimental and control group, outcome indicators [heart rate, LVEF, brain natriuretic peptide (BNP) precursor, adverse events], and so on, was extracted independently by two of the investigators. Any disagreement was resolved through discussion with a third investigator. When relevant data was missing or unclear, we attempted to contact the original author for complete data, and studies without data available were excluded.

\section{Statistical method}

The statistical software RevMan version 5.3 (The Nordic Cochrane Center, The Cochrane Collaboration, Copenhagen) was used for data analysis. Odds ratio (OR) and $95 \%$ confidence interval (CI) were used as the effect value of the count data, and the mean difference (MD) and 95\% CI were used as the effect value of the measurement data. Firstly, a Q test was conducted: (I) when $\mathrm{P}>0.10$ and 

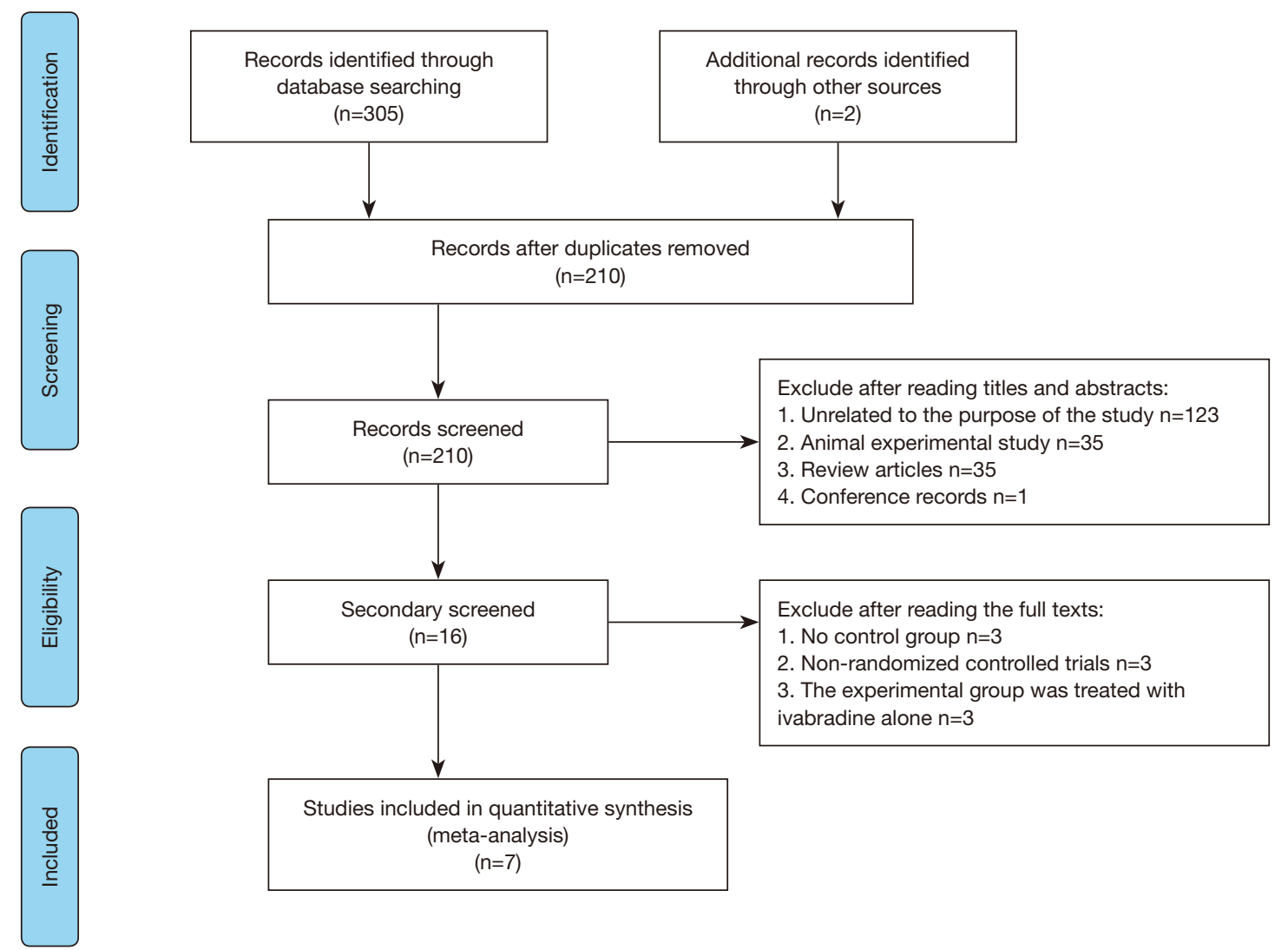

Figure 1 Study selection.

$\mathrm{I}^{2} \leq 50 \%$, there was no significant statistical heterogeneity; the data was thereby analyzed with a fixed effect model in RevMan 5.3; (II) when $\mathrm{P} \leq 0.10$ and $\mathrm{I}^{2}>50 \%$, there was a significant statistical heterogeneity; the data was thereby analyzed with a random effects model in RevMan 5.3; (III) when $\mathrm{P}<0.05$, there was a statistical difference.

\section{Results}

\section{Characteristics of articles}

A total of 307 articles were identified from manual and bibliography searches through the databases. After removal of 97 duplicates in our primary search, 123 irrelevant articles, 35 experimental animal studies, 35 reviews, and 1 meeting minutes were excluded by screening for title and abstract. The remaining 16 articles were re-screened by full-text screening. There were 3 articles without a control group, 3 non-RCTs, and 3 articles with an experimental group treated with ivabradine alone. After the step-bystep screening (Figure 1), 7 articles (Table 1) (10-16) were eventually included. The baseline comparability was "comparable".

\section{Evaluation of the methodological quality of the studies}

All studies (10-16) were RCTs; 1 study (10) applied the computer stochastic method; 6 studies (11-16) reported the random number table method for grouping; 1 study (10) used allocation concealment methods; 1 study (10) mentioned that the investigator and the subjects were blinded; all studies (10-16) contained complete outcome data; all studies (10-16) did not selectively report the results; all studies (10-16) did not mention other sources of bias (Figures 2,3).

\section{Meta-analysis results}

\section{Heart rate}

A total of 6 studies (10-15) (499 patients) reported improved heart rate with ivabradine combined with standard treatment of AMI and statistical heterogeneity 
Table 1 General information of included studies

\begin{tabular}{|c|c|c|c|c|c|c|c|c|c|}
\hline $\begin{array}{l}\text { Authors } \\
\text { (publication } \\
\text { year) }\end{array}$ & Country & \multicolumn{2}{|c|}{ Cases } & \multicolumn{2}{|c|}{ Age $(\bar{X} \pm s)$, years } & \multicolumn{2}{|c|}{ Intervention } & $\begin{array}{l}\text { Follow-up } \\
\text { time }\end{array}$ & Outcomes \\
\hline $\begin{array}{l}\text { Francesco } \\
\text { Barillà } \\
2016,(10)\end{array}$ & Switzerland & $30(21 / 9)$ & $28(18 / 10)$ & $56.3 \pm 9.7$ & $54.4 \pm 10.4$ & $\begin{array}{l}\text { Ivabradine } \\
\text { + standard } \\
\text { therapy }\end{array}$ & $\begin{array}{l}\text { Standard } \\
\text { treatment }\end{array}$ & 4 months & (I), (IIII) \\
\hline $\begin{array}{l}\text { Jiadong Fu } \\
2020,(11)\end{array}$ & China & $34(28 / 6)$ & $34(27 / 7)$ & $63.62 \pm 4.37$ & $63.50 \pm 4.31$ & $\begin{array}{l}\text { Ivabradine } \\
\text { + standard } \\
\text { therapy }\end{array}$ & $\begin{array}{l}\text { Standard } \\
\text { treatment }\end{array}$ & $\begin{array}{c}\text { Not } \\
\text { described }\end{array}$ & (I), (IV) \\
\hline $\begin{array}{l}\text { Jing Liu } \\
2020,(12)\end{array}$ & China & $56(33 / 23)$ & $56(36 / 20)$ & $63.7 \pm 9.7$ & $63.2 \pm 11.7$ & $\begin{array}{l}\text { Ivabradine } \\
\text { + standard } \\
\text { therapy }\end{array}$ & $\begin{array}{l}\text { Standard } \\
\text { treatment }\end{array}$ & 6 months & (I), (II), (IV) \\
\hline $\begin{array}{l}\text { Zhen Yang } \\
2019,(14)\end{array}$ & China & $67(45 / 22)$ & $68(46 / 22)$ & $66.31 \pm 8.53$ & $65.18 \pm 8.37$ & $\begin{array}{l}\text { Ivabradine } \\
\text { + standard } \\
\text { therapy }\end{array}$ & $\begin{array}{l}\text { Standard } \\
\text { treatment }\end{array}$ & 2 weeks & (I), (II), (III) \\
\hline $\begin{array}{l}\text { Chenchen } \\
\text { Shen 2019, } \\
\text { (15) }\end{array}$ & China & $25(15 / 10)$ & $25(13 / 12)$ & $53.2[44-67]$ & 51.7 [45-63] & $\begin{array}{l}\text { Ivabradine } \\
\text { + standard } \\
\text { therapy }\end{array}$ & $\begin{array}{l}\text { Standard } \\
\text { treatment }\end{array}$ & $\begin{array}{c}\text { Not } \\
\text { described }\end{array}$ & (I), (III) \\
\hline
\end{tabular}

(I) Heart rate; (II) left ventricular ejection fraction (LVEF); (III) brain natriuretic peptide precursor (NT-proBNP); (IV) the occurrence of adverse reactions.

was observed $\left(\mathrm{P}<0.00001, \mathrm{I}^{2}=88 \%\right)$. The random effects model combined with effect size was used for analysis. As a result, ivabradine combined with standard treatment could significantly reduce heart rate (MD $=-9.20,95 \% \mathrm{CI}:-13.03$ to $-5.38, \mathrm{P}<0.00001)$ (Figure 4). As for sensitivity analysis, no directional changes were observed after the removal of individual studies, suggesting that the results of this study were basically stable (Table 2).

\section{Left ventricular ejection fraction (LVEF)}

A total of 4 studies $(12,13,15,16)(482$ participants) reported improved LVEF with ivabradine combined with standard treatment of AMI and no statistical heterogeneity was observed $\left(\mathrm{P}=0.39, \mathrm{I}^{2}=1 \%\right)$. The fixed-effect model combined with effect size was used for analysis. As a result, ivabradine combined with conventional standard treatment could significantly improve LVEF (MD =3.17, 95\% CI: 2.12 to 4.23, $\mathrm{P}<0.00001)$. The difference between the two groups was statistically significant (Figure 5).

\section{NT-proBNP}

A total of 3 studies $(10,14,15)$ (243 participants) reported improved BNP with administration of ivabradine combined with conventional standard treatment of AMI and no statistical heterogeneity was observed $\left(\mathrm{P}=0.61, \mathrm{I}^{2}=0 \%\right)$. The fixed-effect model combined with effect size was used for analysis. As a result, ivabradine combined with conventional standard treatment could significantly reduce 


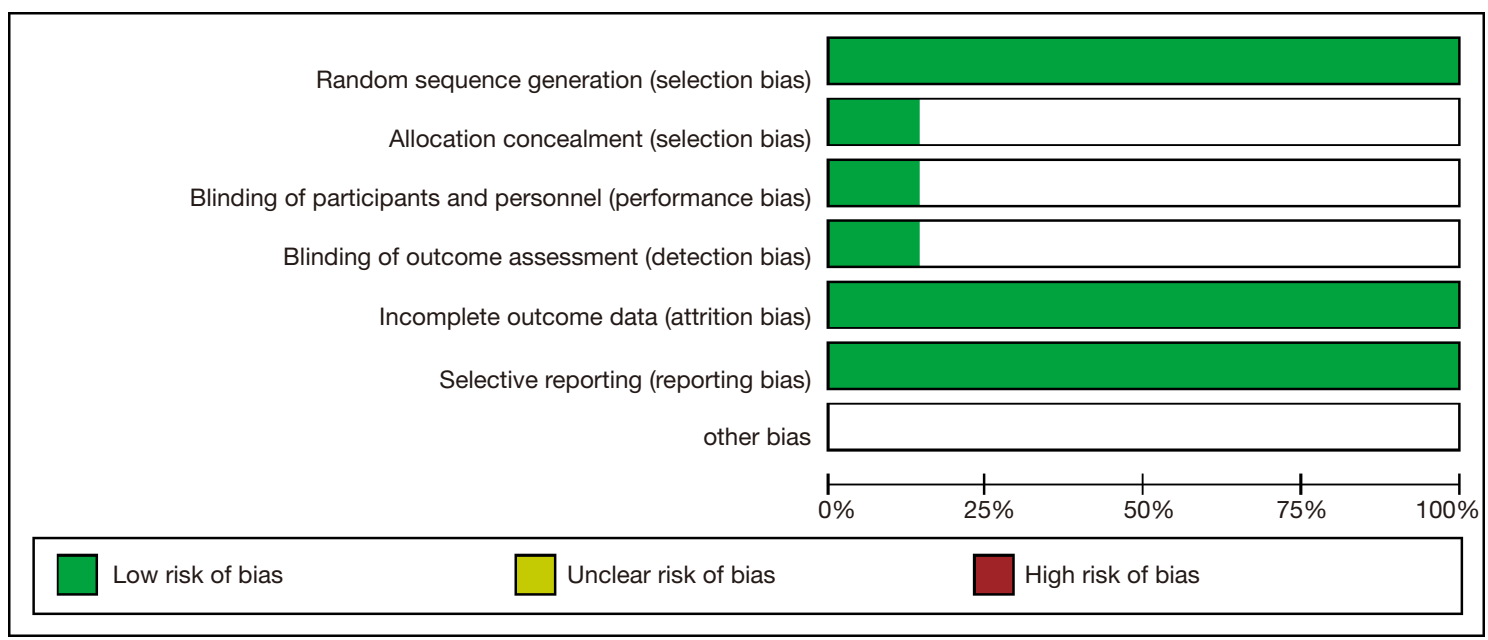

Figure 2 Bar chart of bias risk.

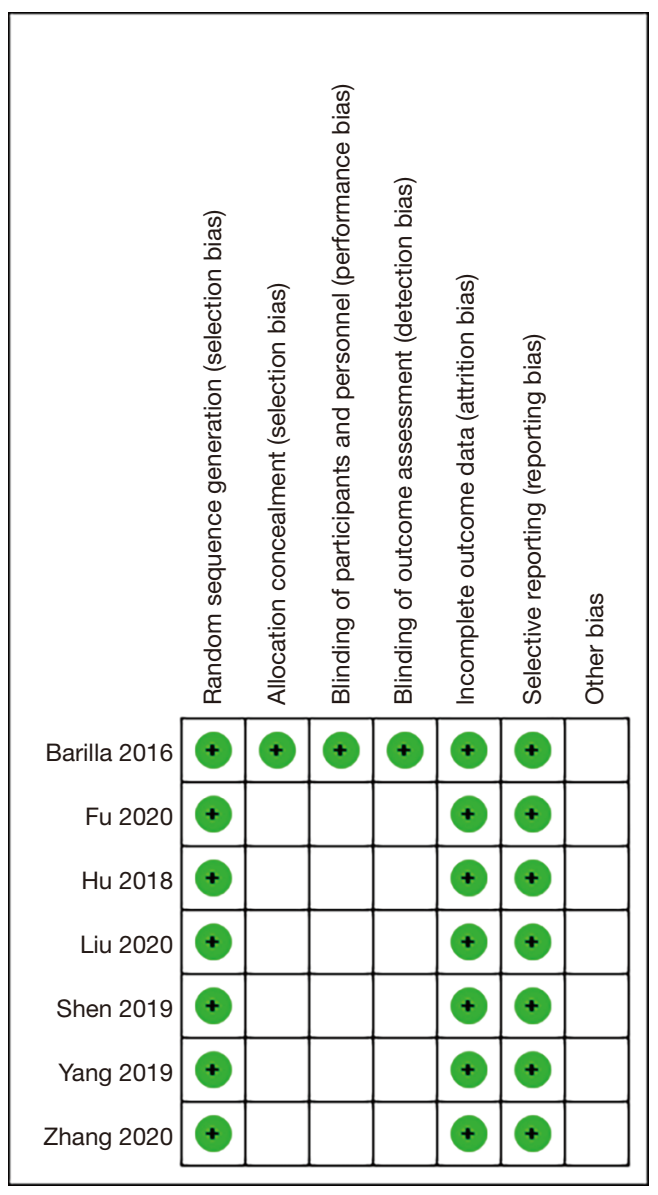

Figure 3 Bias risk chart.
BNP (MD $=-112.73,95 \%$ CI: -186.12 to $-39.35, \mathrm{P}=0.003)$. The difference between the two groups was statistically significant (Figure 6).

\section{Adverse reactions}

A total of 4 studies $(11,12,13,16)(407$ participants) reported adverse events resulting from administration of ivabradine combined with conventional standard treatment of AMI and no statistical heterogeneity was observed $\left(\mathrm{P}=0.91, \mathrm{I}^{2}=0 \%\right)$. The fixed-effect model combined with effect size was used for analysis. As a result, there was no statistically significant difference of adverse events between the two groups (OR $=2.45,95 \%$ CI: 0.92 to $6.55, \mathrm{P}=0.07$ ) (Figure 7).

\section{Discussion}

With the development of society, environmental and human lifestyle changes, the incidence of AMI has increased over recent years, even affecting younger generations and becoming one of the critical causes of death and disability (17). As an independent risk factor of cardiovascular diseases, the increase of resting heart rate is positively associated with the mortality of cardiovascular events from AMI $(18,19)$, which leads to the increase of myocardial oxygen consumption amount, the decrease in coronary artery perfusion, causes myocardial ischemia, an increase in the number of necrotic myocardial cells and the reduction of myocardial compliance, which could 


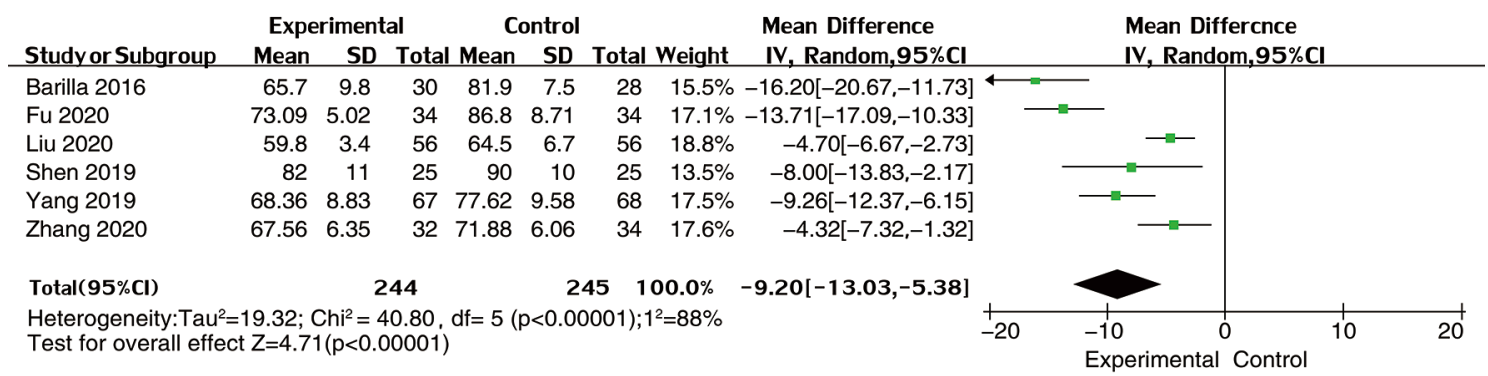

Figure 4 Forest plot of meta-analysis of heart rate in two groups.

Table 2 Results of sensitivity analysis

\begin{tabular}{|c|c|c|c|c|c|c|}
\hline \multirow{2}{*}{ Excluded studies } & \multirow{2}{*}{$\begin{array}{l}\text { Number of cases after } \\
\text { exclusion of studies }\end{array}$} & \multicolumn{2}{|c|}{ Heterogeneity } & \multirow{2}{*}{ Combined model } & \multirow{2}{*}{ MD $(95 \% \mathrm{Cl})$} & \multirow{2}{*}{$P$ value } \\
\hline & & $P$ value & $\mathrm{I}^{2}(\%)$ & & & \\
\hline Francesco Barillà 2016 & 431 & $<0.0001$ & 84 & Random effect & $-7.88(-11.44,-4.33)$ & $<0.0001$ \\
\hline Jiadong Fu 2020 & 421 & $<0.0001$ & 85 & Random effect & $-8.22(-12.03,-4.42)$ & $<0.0001$ \\
\hline Jing Liu 2020 & 377 & $<0.0001$ & 85 & Random effect & $-10.25(-14.54,-5.95)$ & $<0.0001$ \\
\hline Zhen Yang 2019 & 354 & $<0.00001$ & 90 & Random effect & $-9.24(-13.95,-4.52)$ & $<0.00001$ \\
\hline Chenchen Shen 2019 & 439 & $<0.00001$ & 90 & Random effect & $-9.41(-13.72,-5.11)$ & $<0.00001$ \\
\hline
\end{tabular}

$\mathrm{MD}$, mean difference; $\mathrm{Cl}$, confidence interval.

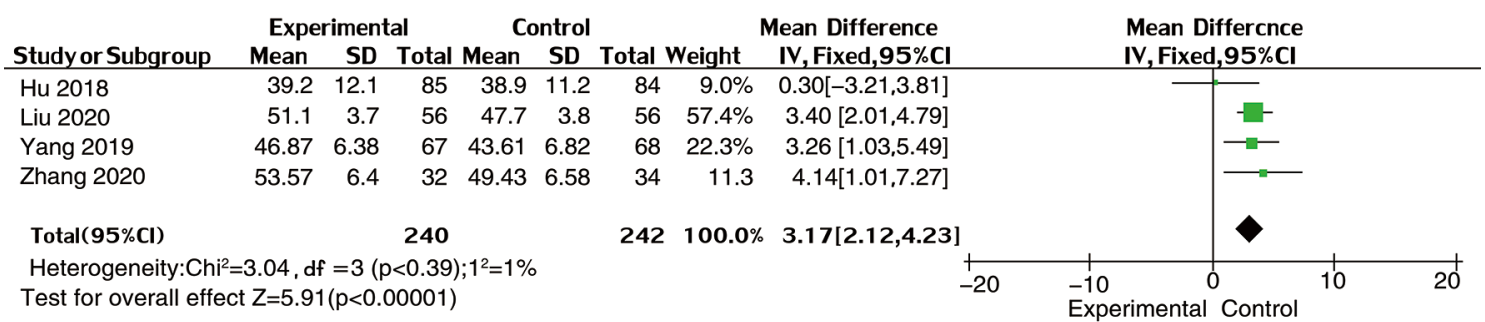

Figure 5 Forest plot of meta-analysis of LVEF in two groups. LVEF, left ventricular ejection fraction.

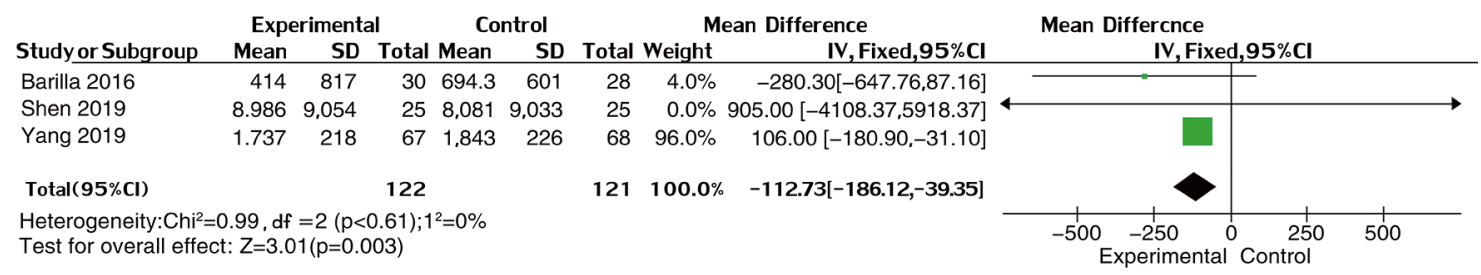

Figure 6 Forest plot of meta-analysis of NT-proBNP in two groups. NT-proBNP, N-terminal pro-brain natriuretic peptide. 


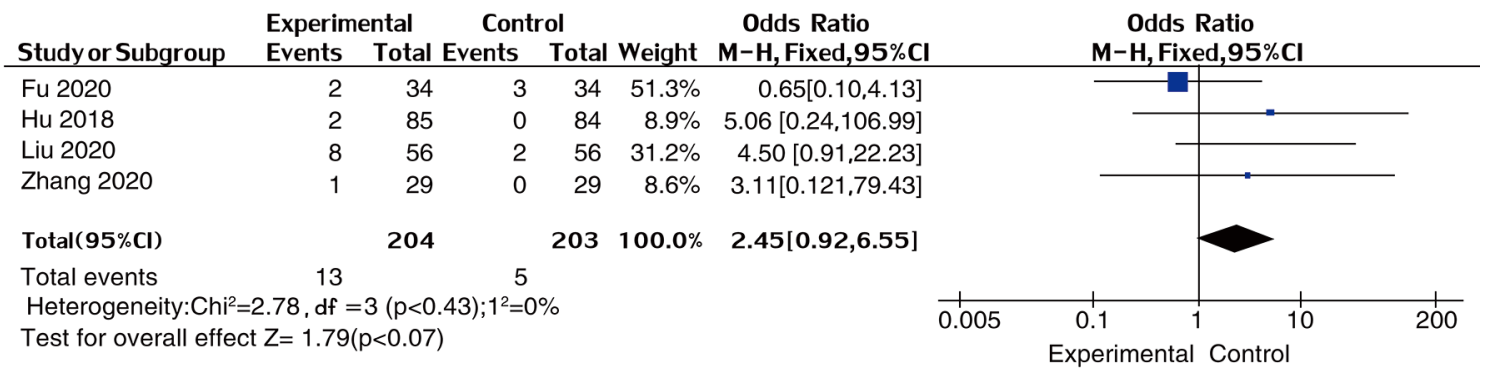

Figure 7 Forest plot of meta-analysis of adverse reactions in two groups.

further cause the heart myocardial remodeling and cardiac function failure (20). Therefore, active clinical control of the resting heart rate has become one of the most important methods for treating AMI (21). Although $\beta$-blockers are clinically used to slow down the heart rate, effects such as negative conduction, negative muscle strength, and lower blood pressure, and side effects and contraindications all require consideration with the clinical application of these drugs (22), which limits its clinical application. Ivabradine, a pacemaker $I_{f}$ current inhibitor, can specifically reduce the rhythm of sinus nodules and slow the heart rate with no additional effects such as negative muscle strength and blood pressure reduction $(23,24)$. Besides, other drugs, such as betablockers, are slower to control heart rate, because the dosage of them need to increase step by step, while ivabradine can more quickly and efficiently control the heart rate without worsening cardiac function (25). The advent of ivabradine has brought a new hope to patients with AMI.

A total of 7 RCTs and 658 participants were included in this meta-analysis. Compared with the control group, the heart rate $(\mathrm{MD}=-9.20,95 \% \mathrm{CI}:-13.03$ to -5.38 , $\mathrm{P}<0.00001)$ and $\mathrm{BNP}(\mathrm{MD}=-112.73,95 \% \mathrm{CI}:-186.12$ to $-39.35, \mathrm{P}=0.003$ ) of the ivabradine combined with conventional standard treatment group were significantly lower and LVEF (MD =3.17, 95\% CI: 2.12 to 4.23 , $\mathrm{P}<0.00001)$ was significantly improved. There was no statistically significant difference in adverse events (OR $=2.45,95 \%$ CI: 0.92 to $6.55, \mathrm{P}=0.07)$. In fact, the safety of ivabradine has been proven in a number of studies and clinical trials. The most common side effects were sinus bradycardia and transitory visual symptoms.

The mechanisms of ivabradine reducing the resting heart rate and improving cardiac function in patients with AMI are as follows: (I) ivabradine can bind to the sinus node $I_{f}$ channel to inhibit the $I_{f}$ current, reduce the sinus node autonomy, and slow down the heart rate
(26,27); (II) slowing down the heart rate can prolong the diastolic period, increase myocardial oxygen supply and coronary perfusion, increase cardiac output, and improve cardiac function; (III) heart rate is positively correlated with ventricular volume and heart rate reduction can reduce ventricular volume load, reduce myocardial work and oxygen consumption, and improve exercise tolerance $(28,29)$. Formed by the degradation of BNP precursor secreted by ventricular myocytes, NT-proBNP is negatively correlated with LVEF and reflects the changes of cardiac function in patients with AMI (30), which can be reduced by ivabradine via improved cardiac function. As reported, heart rate reduction with ivabradine improved outcomes independently of HF duration (31). Reducing HR with ivabradine reduced the rate of cardiovascular death and hospitalization for worsening heart failure in left-ventricular systolic dysfunction but among patients who had stable coronary artery disease without clinical heart failure, the addition of ivabradine to standard background therapy to reduce the heart rate did not improve 3 -month survival rate $(32,33)$.

There were some limitations to this meta-analysis: (I) some studies were without specific randomization methods, allocation concealment, blinding, and so on, and some studies did not mention the reasons for loss to follow-up and withdrawal despite the large sample size included; (II) there might have been a language bias since only English studies were included; (III) the small sample size of a single RCT may have been insufficient to test; only small number of studies were associated with each outcome index; it was not possible to carry out subgroup analysis to evaluate each outcome index; an explanation of heterogeneity was lacking; (IV) the follow-up times were different and not recorded in different studies, and the follow-up time of some studies was too brief. The factors above may affect the accuracy of conclusions of this meta-analysis. More high quality double- 
blind randomized studies are needed to unify the duration of follow-up and the duration of medication to solve the above problems.

To conclude, ivabradine combined with $\beta$-blockers can reduce the resting heart rate and improve heart function in patients with AMI, and the combination is safe and reliable. Our conclusions require further confirmation through analysis of more high-quality studies and more high quality double-blind randomized studies need to be carried out.

\section{Acknowledgments}

Funding: None.

\section{Footnote}

Reporting Checklist: The authors have completed the PRISMA reporting checklist. Available at http://dx.doi. org/10.21037/apm-21-563

Conflicts of Interest: All authors have completed the ICMJE uniform disclosure form (available at http://dx.doi. org/10.21037/apm-21-563). The authors have no conflicts of interest to declare.

Ethical Statement: The authors are accountable for all aspects of the work in ensuring that questions related to the accuracy or integrity of any part of the work are appropriately investigated and resolved.

Open Access Statement: This is an Open Access article distributed in accordance with the Creative Commons Attribution-NonCommercial-NoDerivs 4.0 International License (CC BY-NC-ND 4.0), which permits the noncommercial replication and distribution of the article with the strict proviso that no changes or edits are made and the original work is properly cited (including links to both the formal publication through the relevant DOI and the license). See: https://creativecommons.org/licenses/by-nc-nd/4.0/.

\section{References}

1. White HD, Chew DP. Acute myocardial infarction. Lancet 2008;372:570-84.

2. Dobre D, Kjekshus J, Rossignol P, et al. Heart rate, pulse pressure and mortality in patients with myocardial infarction complicated by heart failure. Int J Cardiol 2018;271:181-5.
3. Salwa P, Gorczyca-Michta I, Wożakowska-Kapłon B. The relationship between admission heart rate and early prognosis in patients with ST-elevation myocardial infarction. Kardiol Pol 2015;73:177-82.

4. El-Battrawy I, Borggrefe M, Akin I. $\beta$-Blockers and Outcome After Acute Myocardial Infarction. J Am Coll Cardiol 2017;70:1685.

5. Fasullo S, Cannizzaro S, Maringhini G, et al. Comparison of ivabradine versus metoprolol in early phases of reperfused anterior myocardial infarction with impaired left ventricular function: preliminary findings. J Card Fail 2009;15:856-63.

6. Mackiewicz U, Gerges JY, Chu S, et al. Ivabradine protects against ventricular arrhythmias in acute myocardial infarction in the rat. J Cell Physiol 2014;229:813-23.

7. Chinese Society of Cardiology of Chinese Medical Association, Editorial Board of Chinese Journal of Cardiology. Guideline for diagnosis and treatment of patients with unstable angina and non-ST-segment elevation myocardial infarction. Zhonghua Xin Xue Guan Bing Za Zhi 2007;35:295-304.

8. Ma L. Interpretation of the new guidelines for the diagnosis and treatment of unstable angina pectoris/nonST segment elevation myocardial infarction. Journal of Clinical Internal Medicine 2007:808-10.

9. Gu H, Wang Y, Li W. Application of Cochrane bias risk assessment tool in meta analysis of randomized controlled trials. Chinese Circulation Journal 2014;29:147-8.

10. Barillà F, Pannarale G, Torromeo C, et al. Ivabradine in patients with ST-elevation myocardial infarction complicated by cardiogenic shock: a preliminary randomized prospective study. Clin Drug Investig 2016;36:849-56.

11. Fu J. The effect of ivabradine in the treatment of acute myocardial infarction with heart failure and its influence on heart rate. Prevention and Treatment of Cardiovascular Disease 2020;10:17-9.

12. Liu J, Zhu Y, Qiu C, et al. Effects of ivabradine on myocardial fibrosis and left ventricular remodeling in patients with ST-segment elevation myocardial infarction and HFrEF type chronic heart failure. Chinese Journal of Hospital Pharmacy 2020;12:1-9.

13. Zhang $\mathrm{W}, \mathrm{Xu} \mathrm{Y}$, Zhong X, et al. Effect of early application of ivabradine on left ventricular remodeling in patients with acute ST segment elevation myocardial infarction. Chinese Journal of Heart Failure and Cardiomyopathy 2020;4:92-7. 
14. Yang Z. Effectiveness of ivabradine in the treatment of acute myocardial infarction complicated with heart failure. Chinese Journal of Urban and Rural Enterprise Hygiene 2019;34:24-6.

15. Shen C. Effect of ivabradine on acute myocardial infarction complicated with heart failure and its influence on cardiac function. Doctor 2019;4:130-1.

16. Hu S, Cao M, Li X, et al. Efficacy of ivabradine in treating acute myocardial infarction patients with heart failure. Jiangsu Medical Journal 2018;44:1428-31.

17. Boateng S, Sanborn T. Acute myocardial infarction. Dis Mon 2013;59:83-96.

18. Ide T, Ohtani K, Higo T, et al. Ivabradine for the Treatment of Cardiovascular Diseases. Circ J 2019;83:252-60.

19. Sharashova E, Wilsgaard T, Mathiesen EB, et al. Resting heart rate predicts incident myocardial infarction, atrial fibrillation, ischaemic stroke and death in the general population: the Tromsø Study. J Epidemiol Community Health 2016;70:902-9.

20. Disertori M, Masè $M$, Rigoni $M$, et al. Heart rate turbulence is a powerful predictor of cardiac death and ventricular arrhythmias in postmyocardial infarction and heart failure patients: a systematic review and metaanalysis. Circulation 2016;9:e004610.

21. Okuno T, Aoki J, Tanabe K, et al. Admission heart rate is a determinant of effectiveness of beta-blockers in acute myocardial infarction patients. Circ J 2019;83:1054-63.

22. Ding Y, Liu J. Analysis of pharmacological characteristics and adverse reactions of metoprolol. Chinese Journal of Clinical Rational Drug Use 2018;11:108-10.

23. DiFrancesco D. Funny channels in the control of cardiac rhythm and mode of action of selective blocker. Pharmacol Res 2006;53:399-406.

24. Swedberg K, Komajda M, Böhm M, et al. Ivabradine and outcomes in chronic heart failure (SHIFT): a randomised placebo-controlled study. Lancet 2010;376:875-85.

Erratum in: Lancet 2010;376:1988.

25. Fang Y, Debunne M, Vercauteren M, et al. Heart rate reduction induced by the if current inhibitor ivabradine improves diastolic function and attenuates cardiac tissue hypoxia. J Cardiovasc Pharmacol, 2012;59:260-7.

26. Shi $\mathrm{S}, \mathrm{Wu} \mathrm{X}$. Clinical research progress of ivabradine in cardiovascular disease. Chinese Circulation Journal 2015;30:613-6.

27. Li C, Jiang D. Study and progress of ivabradine in cardiovascular diseases. Advances in Cardiovascular Diseases 2019;40:143-5.

28. Huang K, Ma W, Zheng C, et al. Clinical study of ivabradine in the treatment of moderate and severe chronic heart failure complicated with sinus tachycardia. Journal of Clinical Cardiology 2017;33:841-5.

29. Ramirez-Carracedo R, Tesoro L, Hernandez I, et al. Ivabradine-stimulated microvesicle release induces cardiac protection against acute myocardial infarction. Int $\mathrm{J}$ Mol Sci 2020;21:6566.

30. Huang G, An S. Assessment of clinical values on $\mathrm{N}$-terminal pro-brain natriuretic peptide in elder patients with heart failure. Chinese Circulation Journal 2014;29:698-701.

31. Böhm M, Komajda M, Borer JS, et al. Duration of chronic heart failure affects outcomes with preserved effects of heart rate reduction with ivabradine: findings from SHIFT. Eur J Heart Fail 2018;20:373-81.

32. Nikolovska Vukadinović A, Vukadinović D, Borer J, et al. Heart rate and its reduction in chronic heart failure and beyond. Eur J Heart Fail 2017;19:1230-41.

33. Fox K, Ford I, Steg PG, et al. Ivabradine in stable coronary artery disease without clinical heart failure. N Engl J Med 2014;371:1091-9.

(English Language Editor: J. Jones)
Cite this article as: Wang B, Zhang X, Chen J, Chen S, Chen Q, Yang S, Wang Q. Effectiveness and safety of ivabradine in the treatment of acute myocardial infarction: a systematic review and meta-analysis. Ann Palliat Med 2021;10(4):4523-4531. doi: 10.21037/apm-21-563 